Die Gegenwart der Geschichte 
RAINER ROTHER

\section{Die Gegenwart der Geschichte}

Ein Versuch über Film

und zeitgenössische Literatur 


\section{CIP-Titelaufnahme der Deutschen Bibliothek}

\section{Rother, Rainer:}

Die Gegenwart der Geschichte : ein Versuch über Film und zeitgenössische Literatur / Rainer Rother. - Stuttgart : Metzler, 1990 ISBN 978-3-476-00695-0 ISBN 978-3-476-03311-6 (eBook) DOI 10.1007/978-3-476-03311-6

Dieses Werk einschließlich aller seiner Teile ist urheberrechtlich geschützt. Jede Verwertung außerhalb der engen Grenzen des Urheberrechtsgesetzes ist ohne Zustimmung des Verlages unzulässig und strafbar. Das gilt insbesondere für Vervielfältigungen, Übersetzungen, Mikroverfilmungen und die Einspeicherung und Verarbeitung in elektronischen Systemen.

(C) 1990 Springer-Verlag GmbH Deutschland Ursprünglich erschienen bei J. B. Metzlersche Verlagsbuchhandlung und Carl Ernst Poeschel Verlag GmbH in Stuttgart 1990 


\section{INHALT}

I. Einleitung $\ldots \ldots \ldots \ldots \ldots \ldots \ldots$

II. Aporien historischer Erkenntnis . . . . . . . . . . . . . . 13

1. Das Verfahren der Vergegenwärtigung . . . . . . . . . 13

2. ". . . ein Schauspiel für den Historiker «. Ernst Jüngers Roman "Eumeswil« . . . . . . . . . . . . . . . 17

3. Kontinuität und Diskontinuität . . . . . . . . . . . 21

4. "Dreitausend Jahre - weggeschmolzen«. Christa Wolfs Erzählung "Kassandra" . . . . . . . . . . . . . . . . 32

5. „Eine Applikation des 'Kapitals` auf die römische Welt«. Der Film "Geschichtsunterricht" von Straub und Huillet . . . . . 37

6. Konzeptionen der Kontinuität der Geschichte . . . . . . . . . 43

III. Die Bestimmung der Aktualität bei Walter Benjamin . . . . 50

IV. Unbestimmtheit der Hoffnung. "Die Patriotin" von Alexander Kluge . . . . . . . . . . . . . . . 66

1. Genese und Resultat . . . . . . . . . . . . . . . . 66

2. Suche nach geeigneten Ansatzpunkten der Näherung . . . . . 76

3. Bruchstücke inszenierter Vergangenheit . . . . . . . . 80

4. Bildlose Nähe . . . . . . . . . . . . . . . 85

5. "Wie kann ich der Geschichte... - entkommen?« . . . . . . 86

6. Die Parteitagssequenz . . . . . . . . . . . . . . 92

V. Erschriebene Kontinuität. »Die Ästhetik des Widerstands« von Peter Weiss . . . . . . . . . . . . . . . . . 96

1. Gefährliche Nähe des Vergangenen . . . . . . . . . . . 97

2. Kreisbewegung. Die Versuchung der lebendigen Bilder . . . . 102

3. Bildbruch . . . . . . . . . . . . . . . . . . . . 115 
4. Das Alte in neuen Begriffen . . . . . . . . . . . . . 122

5. Die Romanfigur als Autor . . . . . . . . . . . . . . . 125

6. Konditional 1 . . . . . . . . . . . . . . . 138

VI. Das konstitutive Ende der Erzählung . . . . . . . . . 146

Anmerkungen . . . . . . . . . . . . . . . 150

Literaturverzeichnis . . . . . . . . . . . . . . . 180 